\title{
Recurrent idiopathic high-flow priapism treated with selective arterial embolization after repeated initial treatments for low-flow priapism
}

\author{
Christopher J.D. Wallis; ${ }^{*}$ Nathan Hoag, BSc (Hon); ${ }^{*}$ Peter J. Pommerville, MD; ${ }^{\dagger}$ Michael E. Huk, MD, FRCPC ${ }^{\ddagger}$
}

\begin{abstract}
High-flow priapism is most often seen following perineal and penile trauma. We report the case of a 32-year-old man who presented with recurrent idiopathic priapism initially treated as low-flow priapism on 8 previous emergency department visits. Pelvic angiography revealed an abnormal communication between the left cavernosal artery and the left corpus cavernosum and led to the diagnosis of high-flow priapism. Treatment involved embolization of the left common penile artery, which resulted in successful resolution of the recurrent priapism. Our patient's case highlights the importance of an appropriate work-up, including imaging, to distinguish high- and low-flow priapism and to provide appropriate care.
\end{abstract}

Can Urol Assoc J 2009;3(1):60-3

\section{Résumé}

Le priapisme à haut débit est le plus souvent observé après un traumatisme périnéal et pénien. Nous décrivons le cas d'un homme de 32 ans atteint de priapisme idiopathique récurrent traité au départ comme un priapisme à bas débit lors de 8 visites antérieures au service des urgences. Une angiographie pelvienne a révélé un passage anormal entre l'artère caverneuse gauche et le corps caverneux gauche et a mené au diagnostic de priapisme à haut débit. Un traitement par embolisation de l'artère pénienne gauche a été réalisé, entraînant la disparition complète du priapisme récurrent. Ce cas illustre l'importance d'une analyse approfondie, notamment à l'aide d'épreuves d'imagerie, afin de distinguer les cas à haut débit des cas à bas débit et de choisir les soins appropriés.

\section{Case report}

We report the case of a 32-year-old white man who presented to the emergency department with a mildly painful erection of 4 hours' duration. Physical examination revealed engorged corpora cavernosa and a soft, well-perfused corpus spongiosum. Results of abdominal and genital examinations were otherwise normal. He had no history of sicklecell disease and no known perineal trauma. A complete hematological work-up failed to reveal evidence of blood dyscrasia. He denied any use of cocaine but admitted to occasional marijuana and alcohol use, though not on the day of presentation. We did not perform a toxicology screen, and the patient was not taking any medications.

In the previous 6 years, the patient had a history of multiple emergency department presentations, including 8 visits for recurrent priapism lasting between 4 and 9 hours. He also experienced many past episodes where he was able to achieve detumescence through conservative measures, including hot showers or warm compresses, without seeking medical care. There were no identified precipitants to these events. Corporal blood gases were taken on 3 of these occasions, and the results revealed acidosis $(\mathrm{pH}: 6.77,6.8$, 6.74) with increased $\mathrm{pCO}_{2}(139,115,120 \mathrm{~mm} \mathrm{Hg})$ and decreased $\mathrm{pO}_{2}(5.9,6,21 \mathrm{~mm} \mathrm{Hg})$, respectively. Radiological investigations were not performed on these admissions. The acidotic blood gases, together with the clinical findings of a painful prolonged erection, led to the working diagnosis of low-flow, or ischemic, priapism. On repeat visits, this presumptive diagnosis was retained and successful detumensence was achieved through irrigation with epinephrine or phenylephrine and saline.

Upon this latest presentation, treatment in the emergency department using conservative techniques was unsuccessful. We performed a colour duplex Doppler flow ultrasound, which demonstrated an arteriovenous fistula between the left cavernosal artery and the corpus cavernosum, suggestive of high-flow priapism (Fig. 1 and Fig. 2). Pelvic angiography of the erect penis did not confirm any abnormality (Fig. 3). Detumescence was achieved using phenylephrine and aspiration of blood from the corporal body. We then performed selective angiography of the left pudendal artery, which showed an enlarged left pudendal artery with direct flow into the left corpora, demonstrating a marked arterial blush (Fig. 4). We performed therapeutic embolization of the left common penile artery without complication using a combination of autologous blood and Gelfoam.

At follow-up 1 month later, there had been no recurrence of priapism, the patients had normal erectile function, and there were no adverse sequelae. There have been no sub- 
sequent presentations to the emergency department or urological office in the 5 months after treatment.

\section{Discussion}

Priapism is a prolonged and persistent penile erection that is unrelated to sexual arousal or stimulation. ${ }^{1,2}$ The spectrum of presentation varies from a few hours to many months, though a qualifying criterion of the clinical definition is that it persists beyond 4 hours. 'Typically, the corpora cavernosa

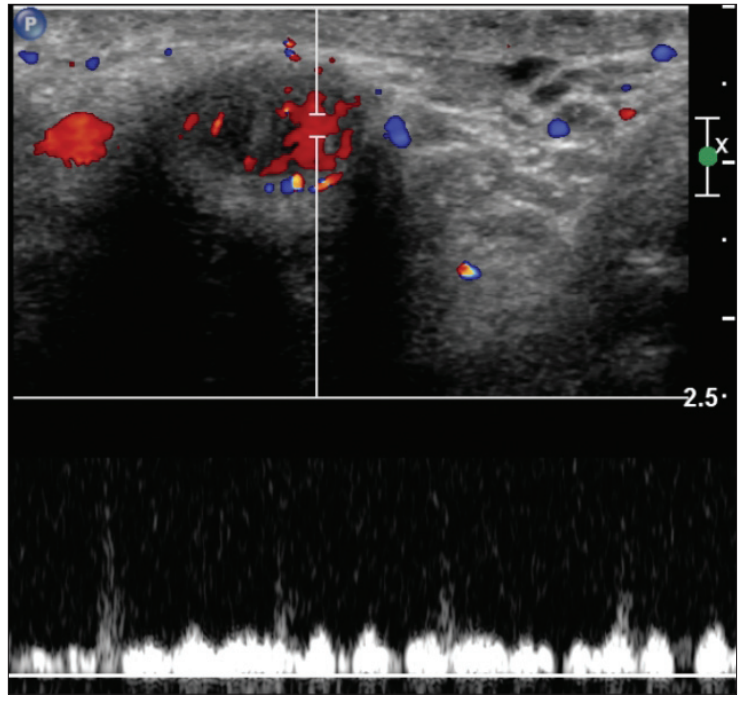

Fig. 1. Colour Doppler ultrasound of the base of the penis (proximal penis) demonstrating arterial flow within the left corporal body. are uncontrollably engorged while the corpus spongiosum is not, though occasionally the corpus spongiosum has been observed to be tumesced.

Three forms of priapism are described: low-flow (ischemic), high-flow (nonischemic) and stuttering priapism. ${ }^{1}$ In high-flow priapism, there is a communication between the cavernous artery and the lacunar spaces of the cavernous tissue, which allows blood to bypass the protective helicine arteriolar bed that is responsible for the high physiologic vascular resistance within the penis. ${ }^{3}$

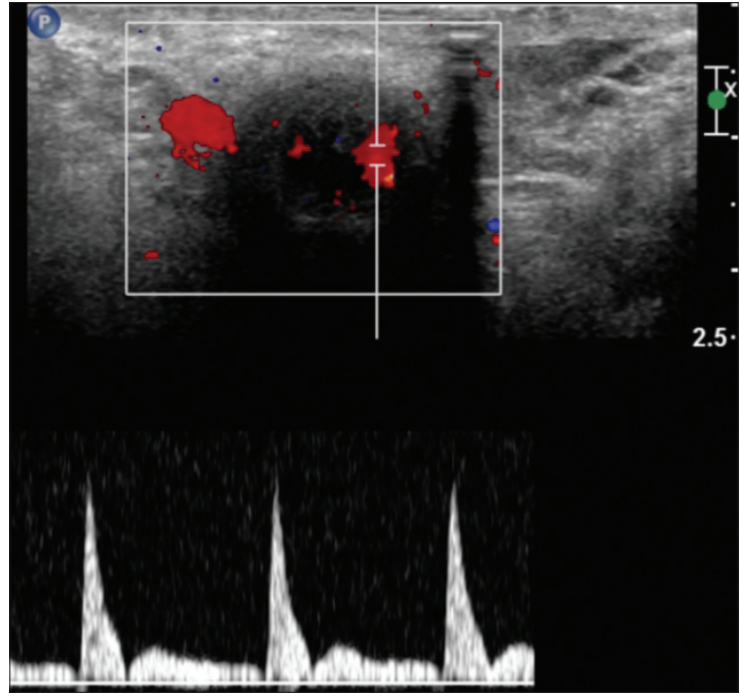

Fig. 2. Colour Doppler ultrasound of the distal penis demonstrating increased venous flow within the corpora.

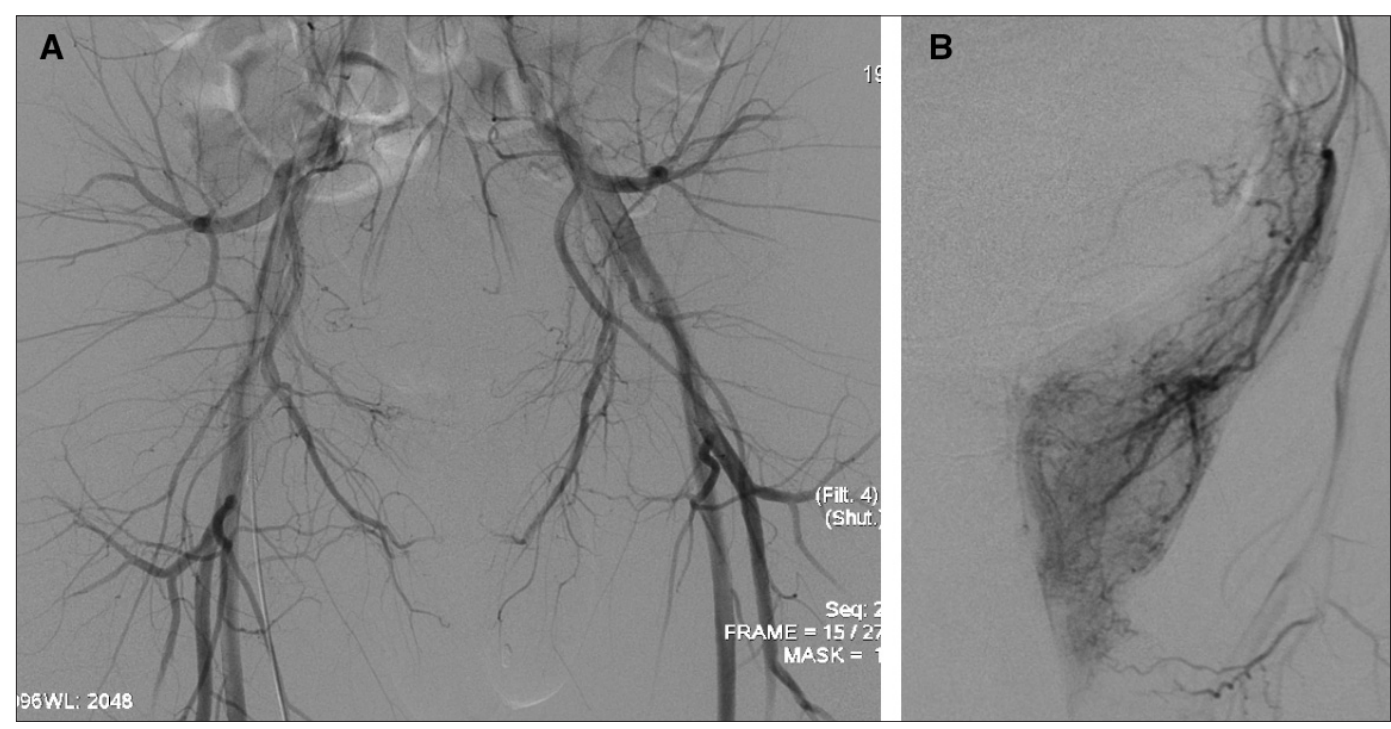

Fig. 3. Pelvic angiography (A) and selective left pudendal angiography (B) prior to detumescence. We observed no difference between the left and right sides. 
The evaluation of priapism should focus on distinguishing between low-flow and high-flow states. Such an evaluation should begin with a thorough history, including the duration of priapism; severity of pain; previous history of priapism and its treatment; the use of precipitating drugs; a history of pelvic, penile, or genital trauma; and a history of hematological dyscrasia. Subsequently, a physical examination is warranted to distinguish between low- and high-flow priapism. Patients with low-flow priapism will often present with rigid corpora cavernosa and penile pain, whereas those with high-flow priapism will often present with tumesced but not rigid corpora cavernosa and seldom report penile pain. Laboratory investigations should include a complete blood count to rule out infection, lymphoma, leukemia, hemaglobinopathies and other blood dyscrasias. A urine toxicology screen should be performed if it is suspected that psychoactive drugs or overdoses of legal or illegal drugs may be implicated in the priapism. Blood gas testing and colour Doppler ultrasonography are considered the most reliable modalities to distinguish low- and high-flow priapism. ${ }^{1}$ However, as our patient's case demonstrates, the use of imaging in the diagnosis of priapism is essential to avoid recurrent inappropriate treatment. In low-flow priapism, blood samples are typically hypoxic and dark with a $\mathrm{pO}_{2}<30 \mathrm{~mm} \mathrm{Hg}$, $\mathrm{pCO}_{2}>80 \mathrm{~mm} \mathrm{Hg}$ and $\mathrm{pH}<7.25$, whereas in high-flow priapism blood samples are normally oxygenated and red with blood gases similar to that of arterial blood. On colour Doppler ultrasonography, low-flow priapism would show little or no blood flow within the cavernosal arter-

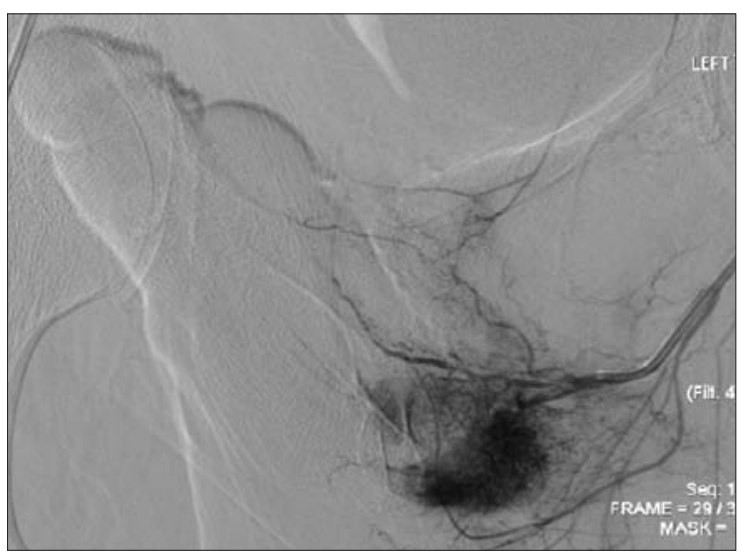

Fig. 4. Selective angiography of the left pudendal artery after detumescence demonstrating marked blush. ies, whereas high-flow priapism would show normal to elevated blood flow velocities. Additionally, sonography may reveal anatomical abnormalities responsible for the priapism. As an adjunct, pelvic angiography may be used to identify and localize a cavernous artery fistula, though this is typically only performed in conjunction with an embolism procedure because colour Doppler ultrasonography has replaced angiography as the diagnostic modality for fistulas. ${ }^{1}$

High-flow priapism is usually associated with penile and perineal trauma. ${ }^{4}$ Additional identified causes of high-flow priapism include vasoactive drugs, penile revascularization surgery and neurologic conditions. ${ }^{2}$

We propose that in our patient's case, the highflow priapism was caused by an anomaly of the left cavernosal artery leading to its communication with the left cavernosal body. High-flow priapism has been described as a complication of the treatment of low-flow priapism. ${ }^{5,6}$ However, angiography in such cases has revealed high flow within the cavernosal arteries in the absence of a cavernosal-sinusoidal fistula. ${ }^{5}$ This further emphasizes the utility of imaging in addition to blood gases in the diagnosis of priapism and in understanding its etiology.

American Urological Association guidelines for the treatment of priapism indicate that all cases of recurrent priapism should be treated aggressively according to the recommendations for ischemic priapism. ${ }^{1}$ Guidelines for the treatment of high-flow priapism indicate that aspiration of the penile blood serves only a diagnostic role. There appears to be no therapeutic value in irrigating with a sympatomimetic agent in cases of high-flow priapism. There may in fact be adverse effects associated with the administration of such agents owing to the unregulated arterial inflow and venous outflow associated with the condition. The recommended initial intervention is observation because high-flow priapism is not a medical emergency, unlike low-flow priapism. If detumescence does not occur naturally, selective arterial embolization is the recommended definitive treatment with autologous clots and absorbable gels being preferred to permanent coils and chemicals. ${ }^{1}$ This approach has proven successful in cases of postsurgical priapism ${ }^{4}$ and posttraumatic priapism.? Furthermore, it has been shown that selective embolization of the fistula is 
a highly effective, safe and well tolerated procedure with normal erectile function typically maintained. ${ }^{8}$ Surgical management including open exploration and direct ligation of sinusoidal fistulas should be considered only in refractory cases and those where a cystic mass with a thick wall is noted on intraoperative duplex ultrasonography. ${ }^{1}$

\section{Conclusion}

Though priapism is a rare condition, it is critical for clinicians to distinguish between low- and highflow priapism because the treatment algorithm differs markedly for these 2 conditions. The use of colour Doppler ultrasonography and a careful history and physical examination are useful in distinguishing between the conditions. Angiography can be used to confirm the diagnosis of high-flow priapism. Selective arterial embolization has been identified as the treatment modality of choice in the case of high-flow priapism.

From the *University of British Columbia, Island Medical Program, University of Victoria, Victoria, BC, †Royal Jubilee Hospital, Division of Urology, Department of Urologic Sciences, University of British Columbia, Victoria, BC, and the fDepartment of Radiology, Victoria General Hospital, Victoria, BC
This article has been peer reviewed.

Competing interests: None declared.

\section{References}

1. Montague DK, Jarow J, Broderick GA, et al. American Urological Association guideline on the management of priapism. J Urol 2003;170:1318-24.

2. Burnett AL, Bivalacqua TJ. Priapism: current principle and practice. Urol Clin North Am 2007:34:631-42.

3. McMahon CG. High flow priapism due to arterial-lacunar fistula complicating initial venoocculsive priapism. Int I Impot Res 2002; 14:195-6.

4. Tuygun C, Guvercinci M, Conkbayir I, et al. Post-surgical high-flow priapism treated with embolization. Int J Urol 2007;14:1107-8.

5. Seftel AD, Haas CA, Brown SL, et al. High flow priapism complicating veno-occlusive priapism: Pathophysiology of reccurent idiopathic priapism? I Urol 1998;159:1300-1.

6. Park JK, Jeong YB, Han YM, et al. High-flow priapism caused by injury of the bilateral cavernosal artery after needle trauma in a patient with low-flow priapism. BJU Int 2003;92:e7-e8.

7. Hellstrom WJG, DeRosa A, Lang E. The use of transcatheter superselective embolization to treat high flow priapism (arteriocavernosal fistula) caused by straddle injury. J Urol 2007:178:1059.

8. Savoca G, Pietropaolo F, Scieri F, et al. Sexual function after highly selective embolization of cavernous artery in patients with high flow priapism: long-term followup. J Urol 2004;172:644-7.

Correspondence: Christopher J.D. Wallis, University of British Columbia, Island Medical Program, University of Victoria, PO Box 1700 STN CSC, Victoria BC V8W 2Y2; wallisc@interchange.ubc.ca.

\section{Change of address}

We require 6 to 8 weeks' notice to ensure uninterrupted service. Please send your current mailing label, new address and the effective date of change to:

\section{CUAJ}

1155 University Ave., Suite 1303

Montréal QC H3B 3A7

fax 514 395-1664

journal@cua.org 